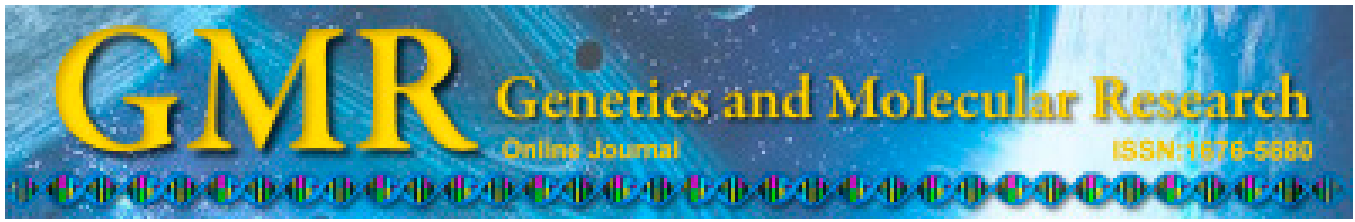

\title{
A case-control study on the risk factors of urinary calculus in Uyghur children in the Kashi region
}

\author{
H.C. Wang ${ }^{1}$, C. Liu ${ }^{1}$, H.Y. He ${ }^{2}$ and M.X. Wang ${ }^{3}$ \\ ${ }^{1}$ Health Management Center, \\ First Affiliated Hospital of Xinjiang Medical University, Urumqi, \\ Xinjiang, China \\ ${ }^{2}$ Department of Nursing, Sichuan College of Traditional Chinese Medicine, \\ Mianyang, Sichuan, China \\ ${ }^{3}$ Department of Nursing, First Affiliated Hospital of Xinjiang Medical University, \\ Urumqi, Xinjiang, China
}

Corresponding author: M.X. Wang

E-mail: MeixinWangcn@126.com

Genet. Mol. Res. 14 (4): 5862-5869 (2015)

Received May 30, 2014

Accepted October 7, 2014

Published June 1, 2015

DOI http://dx.doi.org/10.4238/2015.June.1.3

\begin{abstract}
The incidence of urinary calculus (UC) is very high in Uyghur children in the Kashi region of Xinjiang, China, which seriously affects the growth and life quality of these children. This study was aimed at investigating the risk factors of UC in Uyghur children in Kashi region. One hundred fifteen Uyghur children (age $<7$ years) with UC who were treated in First People's Hospital in Kashi were enrolled in the case group. A 1:1 case-control study with a questionnaire was performed. The results showed that, among the 115 UC patients, there were more boys $(71.3 \%)$ than girls (28.7\%), and most cases had an onset age of $1-3$ years $(75.7 \%)$. A lower than primary school education in the mother, drinking unboiled water, water intake $<500 \mathrm{~mL} /$ day, and eating too much sweets were risk factors [odds ratio $(\mathrm{OR})=2.385,9.160,3.263$, and 8.945, respectively], whereas vegetable intake and exposure to summer sunshine of $<2 \mathrm{~h} /$ day were
\end{abstract}


protective factors against $\mathrm{UC}$ onset $(\mathrm{OR}=0.154$ and 0.344 , respectively). Analysis of UC-related factors in 99 cases of $<3$-year-old children revealed that breastfeeding was also a protective factor $(\mathrm{OR}=0.007)$, whereas frequent cow's milk intake within 5 months $(\mathrm{OR}=2.414)$ and frequent "panada" intake $(\mathrm{OR}=2.529)$ were risk factors. The occurrence of UC in Uyghur children in the Kashi region is mainly affected by maternal educational background, quality of drinking water, water intake volume, and dietary pattern. Furthermore, geography may also have a role.

Key words: Children; Urinary calculus; Risk factor; Case-control study

\section{INTRODUCTION}

With increasing economic development, as well as changes in people's lifestyle and diet structures, the incidence of urinary calculus (UC) has also shown an increasing trend (Milosevic et al., 2014), and it has become one of the common diseases that pose a serious threat to human health. There are many factors related to the onset of UC; however, no precise etiology has been confirmed yet (Siener, 2006). Various domestic and international studies have confirmed that the etiology of UC is closely related to environmental factors (Finlayson, 1974; Embon et al., 1990; Leusmann et al., 1990), as well as to genetic factors, ethnicity, gender, age, dietary habits, urinary biochemical abnormalities, etc. (Siener, 2006; Park et al., 2010; Kirejczyk et al., 2014). Previous reports (Nishijima et al., 2002; Lin et al., 2011) have stated that polymorphism of the vitamin D receptor gene is also related to the development of UC.

Because of the special geographical conditions of Xinjiang, China, the Kashi area is mainly populated by the Uyghur people, who have very different genetic backgrounds, eating habits, and child-feeding patterns from the rest of the Chinese population. The onset of UC is early in the Uyghur population, and the youngest patient reported was only 2 months old (Kit et al., 2008). The incidence and recurrence rates of UC are very high, which seriously affects the growth and life quality of the affected children, and has certain impacts on the health and social economy of the entire population. Therefore, understanding the risk factors of UC in children in this region is important to reduce the incidence of the disease and allow developing preventive measures.

At the present, findings about the risk factors of UC were merely from regional epidemiological studies, and no study has done a case-control investigation of the risk factors of the disease. In this study, the related factors of $\mathrm{UC}$ in children in the Kashi region, where pediatric UC has the highest incidence, were investigated by using the 1:1 case-control study method. The objective is to provide a reference study for the prevention of UC in Uyghur children in the Kashi region.

\section{MATERIAL AND METHODS}

\section{Subjects}

One hundred fifteen Uyghur children with UC in Kashi area (Xinjiang, China), hospitalized in the Department of Urology of First People's Hospital of Kashi from November 2009 to June 2011, were enrolled in this study (case group). According to the diagnostic criteria, all cases were confirmed as UC by means of urinary B-ultrasound and radiographic evaluation. The 
inclusion criteria were as follows: 1) children with a confirmed diagnosis of UC, with complete clinical data; 2 ) children of Uyghur ethnicity and aged $<7$ years; and 3 ) children with a signed informed consent form from the legal guardian. The exclusion criteria were as follows: 1) children whose legal guardians refused participation even after receiving an explanation of the study from the researchers; 2) children with renal failure, chronic urinary system disorders, hyperparathyroidism, and other diseases; and 3) children considered to be unsuitable to the study.

The control group was selected from other inpatients or outpatients who do not have UC in the same period. The subjects in the control group had the same gender, nationality, township or street residence (or were from a neighboring town or street), and age (range, \pm 1 year) with those in the case group. The selection into the two groups was in accordance with the principle of 1:1 individual matching. Children with a history of chronic urinary system diseases or severe renal failure were excluded. Written informed consent was obtained from the guardian of all participants.

\section{Questionnaire tools}

A self-designed questionnaire containing items about the related factors of pediatric UC onset was used to collect the information of subjects as follows: 1) general information: nationality, gender, age, place of birth, place of residence, body weight, and history of urinary tract diseases; 2) familial information: income, educational levels, occupation, and family history of urinary tract diseases in both parents; 3 ) dietary conditions and living habits; 4) degree of the parents' knowledge about UC; and 5) levels of biochemical indicators, obtained from clinical data with the consent of the hospital. The investigation was performed by specially trained investigators by using a uniform quantitative criteria.

\section{Questionnaire methods}

The questionnaire for this survey was uniformly distributed and collected in person by trained Uyghur investigators. The investigators fully explained the purpose and significance of this study to the guardians. After obtaining their cooperation and signed informed consent, a one-to-one field investigation was performed.

\section{Data processing and statistical analysis}

The obtained data were input into the Epidata 3.0 software by two researchers. A special database was created for data checking. The multivariate logistic regression model was used for the analysis, including calculations and adjustments of the odds ratio (OR) and 95\% confidence interval $(95 \% \mathrm{CI}) . \mathrm{P}<0.05$ was considered to be significantly different.

\section{RESULTS}

\section{Main variables and assignments}

On the basis of a single-factor analysis, combined with specialized knowledge, a stepwise multivariate logistic regression was performed, and the variables and assignments are shown in Table 1. 


\begin{tabular}{|c|c|c|}
\hline Variable & & Assignment \\
\hline $\mathrm{UC}$ & $\mathrm{Y}$ & Control $=0$, case $=1$ \\
\hline Breastfeeding & $\mathrm{X}_{1}$ & No $=0$, yes $=1$ \\
\hline Artificial feeding & $\mathrm{X}_{2}$ & No $=0$, yes $=1$ \\
\hline Cow milk & $\mathrm{X}_{3}^{2}$ & No $=0$, yes $=1$ \\
\hline Panada & $\mathrm{X}_{4}^{3}$ & No $=0$, yes $=1$ \\
\hline Crusty pancake & $X_{5}^{4}$ & No $=0$, yes $=1$ \\
\hline Educational level of mother & $X_{6}^{3}$ & Primary and under $=1$, secondary $=2$, high school and above $=3$ \\
\hline Type of common drinking water & $\mathrm{X}_{7}^{6}$ & Running water $=1$, well water $=2$, ditch water $($ or river water $)=3$ \\
\hline Water drinking habit & $X_{8}$ & $\begin{array}{l}\text { Drinking according to the need }=1 \text {, drinking according to the time point }=2 \text {, } \\
\text { Drinking according to the time point and volume }=3\end{array}$ \\
\hline Daily water drinking volume & $\mathrm{X}_{9}$ & Small $=1$, normal $=2$, lot $=3$ \\
\hline Fruit/vegetable/dried nuts & $\mathrm{X}_{10}$ & Small $=1$, normal $=2$, lot $=3$ \\
\hline Sweet foods & $X_{11}^{10}$ & None $=1$, occasionally $=2$, frequently $=3$ \\
\hline Summer/winter outdoor activity times & $\mathrm{X}_{12}$ & $<2 \mathrm{~h}=1,2-4 \mathrm{~h}=2,>4 \mathrm{~h}=3$ \\
\hline
\end{tabular}

\section{Age and gender distribution of the 115 children with UC}

The age and gender distribution of the 115 Uyghur children with UC Uyghur are shown in Table 2. Among the 115 patients, there were more boys (71.3\%) than girls (28.7\%). Most of the children with UC were within 1-3 years old, accounting for $75.7 \%$ of the total number.

\begin{tabular}{|c|c|c|c|c|c|c|}
\hline \multirow[t]{2}{*}{ Age (years) } & \multicolumn{2}{|c|}{ Girls } & \multicolumn{2}{|c|}{ Boys } & \multicolumn{2}{|c|}{ Total } \\
\hline & $\mathrm{N}$ & Proportion (\%) & $\mathrm{N}$ & Proportion (\%) & $\mathrm{N}$ & Proportion (\%) \\
\hline$<1$ & 2 & 6.1 & 10 & 12.2 & 12 & 10.4 \\
\hline $1-3$ & 27 & 81.8 & 60 & 73.2 & 87 & 75.7 \\
\hline$>3$ & 4 & 12.1 & 12 & 14.6 & 16 & 13.9 \\
\hline Total & 33 & 100.0 & 82 & 100.0 & 115 & 100.0 \\
\hline
\end{tabular}

\section{Multivariate logistic regression analysis in 1-3-year-old Uyghur children with UC}

Multivariate logistic regression analysis was performed in 99 cases of the 1-3-yearold group and in the control group, and the results are shown in Table 3. Breastfeeding was found to be a protective factor against $\mathrm{UC}(\mathrm{OR}=0.007,95 \% \mathrm{CI}=0.001-0.089)$.

Table 3. Multivariate logistic regression analysis in 1-3-year-old Uyghur children with UC.
\begin{tabular}{lccrrrr}
\hline Factor & \multicolumn{1}{l}{ B } & SE & Wald & P & OR & $95 \%$ CI \\
\hline Breastfeeding & -4.901 & 1.266 & 14.975 & $<0.001^{*}$ & 0.007 & $0.001-0.089$ \\
Frequent cow milk intake in 5 months & 0.881 & 0.424 & 4.324 & $0.038^{*}$ & 2.414 & $1.052-5.540$ \\
Frequent panada intake in 5 months & 0.928 & 0.367 & 6.389 & $0.011^{*}$ & 2.529 & $1.232-5.194$ \\
\hline
\end{tabular}

$* \mathrm{P}<0.05$, significantly different.

\section{Multivariate logistic regression analysis in $<7$-year-old Uyghur children with UC}

A multivariate logistic regression analysis was performed in 115 cases of $<7$-yearold Uyghur children with UC and in 115 controls. As shown in Table 4, a lower than primary school education in the mother, frequent drinking of unboiled water, drinking less water 
daily, and frequent intake of sweets were the common risk factors of UC in Uyghur children, whereas frequent intake of vegetables and exposure to summer sunshine of $<2 \mathrm{~h} /$ day were the common protective factors against UC.

Table 4. Multivariate logistic regression analysis in $<7$-year-old Uyghur children with UC

\begin{tabular}{lccrcc}
\hline Factor & $B$ & SE & P & OR & $95 \%$ CI \\
\hline Mother's educational level lower than primary school & 0.869 & 0.272 & 0.001 & 2.385 & $1.401-4.061$ \\
Frequent drinking of unboiled water & 2.215 & 0.513 & $<0.001$ & 9.160 & $3.354-25.015$ \\
Drinking less water daily & 1.183 & 0.348 & 0.001 & 3.263 & $1.605-6.332$ \\
Frequent intake of sweets & 2.191 & 0.547 & $<0.001$ & 8.945 & $3.062-26.133$ \\
Frequent intake of vegetables & -1.868 & 0.546 & 0.001 & 0.154 & $0.053-0.450$ \\
Exposure to summer sunshine $<2$ h/day & -1.068 & 0.217 & $<0.001$ & 0.344 & $0.224-0.526$ \\
\hline
\end{tabular}

\section{DISCUSSION}

\section{Age and gender distribution in Uyghur children with UC}

In this study, among the 115 children with UC, there were more boys (71.3\%) than girls $(28.7 \%)$. In previous studies, there was no conclusion about whether gender is a risk factor of UC (Novak et al., 2009). In developing countries, the gender ratio of pediatric UC was 3:1 boys:girls (Rizvi et al., 2002), and the overall UC incidence in China was also higher among male patients than in female patients, with the ratio as 2.5: 1 (Daudon et al., 2004). In this study, the boys:girls ratio in the UC case group was 2.5:1, which is consistent with previous studies. A national survey in the United States that covered 36 states revealed that boys were prone to develop UC in the first decade after birth, whereas girls tend to develop UC in the second decade after birth, and the reason might be related to the hormonal differences between the sexes in this age group (Novak et al., 2009). Concerning the age of onset, Kamoun et al. (1999) reported that 40 to $50 \%$ of UC cases occurred in children $<5$ years old, and $20 \%$ occurred in those $<2$ years old. Meanwhile, as shown in Table 2, this study reveals that the 1-3-year-old group had the highest incidence of UC in this study, accounting for $75.7 \%$. Children in this age group had just ended lactation; thus, an imbalance between growth demand and diet structure might be the main cause of disease development in this age group.

\section{Analysis of the relevant factors in 99 cases of $<3$-year-old Uyghur children with UC}

The multivariate analysis (Table 3 ) revealed that breastfeeding was a protective factor against $\mathrm{UC}(\mathrm{OR}=0.007,95 \% \mathrm{CI}=0.001-0.089)$. Cillo et al. (2001) also evaluated the risk factors of UC by using urine samples from healthy infants. Their results showed that urine components that could cause UC (including calcium, uric acid, and oxalic acid) were higher in artificially feeding infants than in breastfeeding infants, which might be one of the reasons why artificially fed infants had a higher UC risk. Their research showed that pure breastfeeding could meet the dietary requirements of infants within 6 months, whereas the early introduction of solid foods would more easily cause the occurrence of growth retardation (Fein et al., 2008).

This study showed that breastfeeding was a protective factor against UC onset, which was related to the rich cow milk resources in the Kashi agricultural and pastoral region. The milk is normally fed to infants at a certain dilution ratio without processing. Therefore, the in- 
fants could not digest and absorb the milk components. Meanwhile, the calcium, phosphorus, and other mineral contents in cow milk are higher than those found in the mother's milk. The data revealed that excessive intake of dairy milk could increase the absorption of calcium and phosphorous (Tekin et al., 2000); thus, long-term consumption of pure cow milk might result in an in vivo disorder of calcium and phosphorus metabolism in the infants, which then could promote the development of UC.

\section{Analysis of relevant factors in 115 cases of $<7$-year-old Uyghur children with UC}

Table 4 shows that the multivariate logistic regression analysis finally confirmed that the common risk factors for UC in Uyghur children include a maternal educational level of below primary school or lower, frequent drinking of unboiled water, drinking less water daily, and frequent intake of sweets. In contrast, the common protective factors were eating more vegetables and exposure to summer sunshine of $<2 \mathrm{~h} /$ day.

In this study, an educational level of primary school or lower in the mother was one of the risk factors of $\mathrm{UC}(\mathrm{OR}=2.385,95 \% \mathrm{CI}=1.401-4.061)$. The Kashi area is inhabited by the Xinjiang Uyghur people. The levels of rural economic development and compulsory education in this area are lagging behind those of the central cities in China. At the same time, because of traditional customs and economic conditions, the marriage and childbearing ages in this population are between 15 and 20 years; thus, the educational background of the women is mainly at the primary and secondary school levels, and the mental state of the mothers is considered to be immature. Because of the vast area of the Kashi region and its small population, the inhabitants of this region have little access to scientific knowledge and parenting information. Moreover, the traditional styles of childrearing and home management (passed on from parents to children) could not meet the nutritional needs of the infants during the different stages of growth and development. Altogether, these factors could lead to the health and nutritional status of the children being below the normal standards, thus increasing their UC risk.

In the survey, drinking unboiled water $(\mathrm{OR}=9.160,95 \% \mathrm{CI}=3.354-25.015)$ was one of the risk factors of UC. It was previously reported that, because of natural and man-made factors, water in the Kashi region shows high hardness, high chloride contents, and high sulfate contents. Furthermore, water in some areas has relatively high contents of arsenic and mercury. Nevertheless, $70 \%$ of the population in this area drink tap water, whereas the remaining 30\% drink well water (treated groundwater). As alumen $\left[12 \mathrm{H}_{2} \mathrm{O}-\mathrm{AlK}\left(\mathrm{SO}_{4}\right)_{2}\right]$ and bleach (main ingredient: calcium hypochlorite) are used for the disinfection and purification of tap water, this kind of water must be boiled and allowed to stand for 3-5 min (to precipitate the particles) before drinking. According to the survey, the qualification rate of well water in the Kashi region was about $40.0 \%$. Frequent drinking of this kind of unboiled water would seriously affect the health of the children and increase their UC risk.

In the results of the multivariate analysis, a daily water consumption of $<500 \mathrm{~mL}$ was one of the risk factors of $\mathrm{UC}(\mathrm{OR}=3.263,95 \% \mathrm{CI}=1.605-6.332)$. The physiological requirements for daily water intake in children are as follows: $<1$ year old, $110-155 \mathrm{~mL} / \mathrm{kg} ; 1-4$ years old, $100-150 \mathrm{~mL} / \mathrm{kg}$; $4-7$ years old, $90-110 \mathrm{~mL} / \mathrm{kg}$; $>7$ years old, $70-85 \mathrm{~mL} / \mathrm{kg}$. Therefore, a daily water intake of $<500 \mathrm{~mL}$ could not meet the physiological needs of the children (Worcester and Coe, 2008). Water intake directly determines the urine output and saturation. The fact that drinking sufficient water could prevent the development of UC has already been confirmed in multiple observational and experimental epidemiological studies. A lower daily 
water intake would decrease the urine output, resulting in increased urine saturation and promoting crystalline precipitation and UC development. In contrast, a large intake of water could increase the urine output and reduce the concentrations of calcium, oxalate, and urate (Parivar et al., 1996). Meanwhile, a higher amount of water could also prevent the polymerization of urinary mucin, thereby reducing the likelihood of kidney stone formation (Borghi et al., 1999). It was found during the survey that most children in the case group could not meet the physiological requirement for daily water intake. The reason might be that the children did not have independent living skills and the parents were lacking in awareness. Therefore, good waterdrinking habits should be established in children, and encouraging a high water intake would be one of the important measures for preventing UC.

It was suggested that the development of UC was also related to food composition. Food composition could be used as a basis in determining the UC incidence in any society; however, other factors could contribute to the promotion or prevention of using this basis (Acar et al., 2008). The results of this study revealed that frequent intake of sweets might be a risk factor of $\mathrm{UC}$ onset $(\mathrm{OR}=8.945,95 \% \mathrm{CI}=3.062-26.133)$, which is consistent with the national adult UC findings (Battino et al., 2002). This might be related to the intake of various sugar-rich fruits (sugar content as high as 10 to $20 \%$ ) such as grapes, Hami melon, and red dates. The habit of eating fresh fruits in summer and dried fruits in winter, as well as their long-term and unrestricted consumption, could increase the risk of UC development by increasing the urinary calcium excretion. This is because sugar could promote intestinal calcium absorption, thus correspondingly increasing the absorption of oxalate. Furthermore, glucose, sucrose, and starch could reduce the $\mathrm{pH}$ of urine and increase the excretions of uric and oxalic acids, thus increasing the risk of formation of uric acid stones, oxalate stones, and calcium-containing calculus (Mora, 1989). Therefore, although the energy supply and nutritional needs of children should be ensured, the intake of high-sugar foods should be restricted to reasonable amounts in order to prevent UC occurrence.

Frequent vegetable intake was found to be one of the protective factors against UC $(\mathrm{OR}=0.154,95 \% \mathrm{CI}=0.053-0.450)$. Plant fibers could combine with sugar and animal proteins, thus reducing their absorption rates (Escribano et al., 2014). In addition, most high-fiber vegetables have diuretic effects. The frequent intake of vegetables could reduce the risk of UC development through increasing the amount of urine; in addition, fibronectin could inhibit the endocytosis, aggregation, and adhesion of calcium oxalate crystals in the cells, thereby reducing the risk of kidney stone formation (Tsujihata et al., 2000).

The occurrence of primary urolithiasis has been reported to be closely related to the geographical environment (Rellum et al., 2014). The Kashi region lies in the central region of central Asia, adjacent to the Taklimakan Desert (east), the Karakoram Mountains (south), and Tibet Ali (west), and constrained by other geographical regions. This region is characterized by a continental warm arid climate; experiences dry air, sandstorms, and dust storms throughout the year; and has an average annual rainfall of less than the annual evaporation amount. The results of this study showed that an exposure time to summer sunshine of $<2 \mathrm{~h} /$ day was a protective factor against $\mathrm{UC}$ onset $(\mathrm{OR}=0.344,95 \% \mathrm{CI}=0.224-0.526)$. Children living in this environment exhibit a sustained, chronic dehydration state; correspondingly, their urine output is low, resulting in a highly concentrated urine that contains supersaturated levels of crystalline substances. The urine $\mathrm{pH}$ decreases in this condition, thus improving the risk of calcium or uric acid stone formation. In addition, the longer sunshine would increase the vitamin D synthesis, promoting the absorption of calcium. This would further reduce the urine amount; in contrast, the blood calcium and urinary calcium would increase together with the UC risk. 


\section{REFERENCES}

Acar B, Arikan FI, Emeksiz S and Dallar Y (2008). Risk factors for nephrolithiasis in children. World J. Urol. 26: 627-630.

Battino BS, DeFoor W, Coe F, Tackett L, et al. (2002). Metabolic evaluation of children with urolithiasis: are adult references for supersaturation appropriate? J. Urol. 168: 2568-2571.

Borghi L, Meschi T, Schianchi T, Briganti A, et al. (1999). Urine volume: stone risk factor and preventive measure. Nephron 81 (Suppl 1): 31-37.

Cillo ACP, Cattini H, Boim MA and Schor N (2001). Evaluation of lithogenic elements in urine of healthy newborns. Pediatr. Nephrol. 16: 1080-1083.

Daudon M, Dore JC, Jungers P and Lacour B (2004). Changes in stone composition according to age and gender of patients: a multivariate epidemiological approach. Urol. Res. 32: 241-247.

Embon OM, Rose GA and Rosenbaum T (1990). Chronic dehydration stone disease. Br. J. Urol. 66: 357-362.

Escribano J, Balaguer A, Roqué i Figuls M, Feliu A, et al. (2014). Dietary interventions for preventing complications in idiopathic hypercalciuria. Cochrane Database Syst. Rev. 2: CD006022.

Fein SB, Labiner-Wolfe J, Scanlon KS and Grummer-Strawn LM (2008). Selected complementary feeding practices and their association with maternal education. Pediatrics 122: S91-S97.

Finlayson B (1974). Symposium on renal lithiasis: renal lithiasis in review. Urol. Clin. North Am. 1: 181-212.

Kamoun A, Daudon M, Abdelmoula J, Hamzaoui M, et al. (1999). Urolithiasis in Tunisian children: a study of 120 cases based on stone composition. J. Pediatr. Nephrol. 13: 920-925.

Kirejczyk JK, Porowski T, Konstantynowicz J, Kozerska A, et al. (2014). Urinary citrate excretion in healthy children depends on age and gender. Pediatr. Nephrol. 4: 88-94.

Kit LC, Filler G, Pike J and Leonard MP (2008). Pediatric urolithiasis: experience at a tertiary care pediatric hospital. Can. Urol. Assoc. 2: 381-386.

Leusmann DB, Blaschke R and Schmandt W (1990). Results of 5,035 stone analyses: a contribution to epidemiology of urinary stone disease. Scand. J. Urol. Nephrol. 24: 205-210.

Lin Y, Mao Q, Zheng X, Chen H, et al. (2011). Vitamin D receptor genetic polymorphisms and the risk of urolithiasis: a meta-analysis. Urol. Int. 12: 1-7.

Milosevic D, Batinic D, Turudic D, Batinic D, et al. (2014). Demographic characteristics and metabolic risk factors in Croatian children with urolithiasis. Eur. J. Pediatr. 173: 353-359.

Mora JO (1989). A new method of estimating a standardized prevalence of child malnutrition from anthropometric indicators. Bull. World Health Organ. 67: 133.

Nishijima S, Sugaya K, Naito A, Morozumi M, et al. (2002). Association of vitamin D receptor gene polymorphism with urolithiasis. J. Urol. 167: 2188-2191.

Novak TE, Lakshmanan Y, Trock BJ, Gearhart JP, et al. (2009). Sex prevalence of pediatric kidney stone disease in the United States: an epidemiologic investigation. Urology 74: 104-107.

Parivar F, Low RK and Stoller ML (1996). The influence of diet on urinary stone disease. J. Urol. 155: 432-440.

Park C, Ha YS, Kim YJ, Yun SJ, et al. (2010). Comparison of metabolic risk factors in urolithiasis patients according to family history. Korean J. Urol. 51: 50-53.

Rellum DM, Feitz WF, van Herwaarden AE and Schreuder MF (2014). Pediatric urolithiasis in a non-endemic country: a single center experience from The Netherlands. J. Pediatr. Urol. 10: 155-61.

Rizvi SA, Naqvi SA, Hussain Z, Hashmi A, et al. (2002). Pediatric urolithiasis: developing nation perspectives. J. Urol. 168: $1522-1525$.

Siener R (2006). Impact of dietary habitson stone incidence. Urol. Res. 34: 131-133.

Tekin A, Tekgul S, Atsu N, Sahin A, et al. (2000). A study of the etiology of idiopathic calcium urolithiasis in children: hypocitruria is the most important risk factor. J. Urol. 164: 162-165.

Tsujihata M, Miyake O, Yoshimura K, Kakimoto KI, et al. (2000). Fibronectin as a potent inhibitor of calcium oxalate urolithiasis. J. Urol. 164: 1718.

Worcester EM and Coe FL (2008). Nephrolithiasis. Prim. Care 35: 369-391. 